\title{
Paisagens semióticas e imigração em São Paulo
}

\section{Semiotic landscapes and immigration in São Paulo}

Alexandre Marcelo BUENO*

\begin{tabular}{|c|c|}
\hline $\begin{array}{l}\text { RESUMO: A dinâmica cultural e } \\
\text { econômica da cidade de São Paulo, tanto } \\
\text { no passado como no presente, tem como } \\
\text { um de seus principais atores a alteridade } \\
\text { vinda de outro país: refugiados e } \\
\text { imigrantes. Diversos grupos imigrantes } \\
\text { imprimem marcas de sua presença no } \\
\text { espaço de diferentes bairros. Este trabalho } \\
\text { tem por objetivo observar e analisar } \\
\text { elementos da presença de imigrantes e } \\
\text { refugiados demarcados no espaço público } \\
\text { de bairros paulistanos, como, por } \\
\text { exemplo, as línguas estrangeiras e o } \\
\text { comércio imigrante. É por meio desses } \\
\text { elementos que poderemos refletir sobre as } \\
\text { dinâmicas da relação entre o local e o } \\
\text { global, com sua transformação ou sua } \\
\text { negação por meio das instâncias espaciais } \\
\text { locais. Como uma espécie de estudo de } \\
\text { caso, ainda provisório, examinamos uma } \\
\text { rua da comunidade boliviana na cidade } \\
\text { de São Paulo. Observamos, inicialmente, } \\
\text { como há práticas mistas que se } \\
\text { manifestam tanto no uso linguístico como } \\
\text { no uso de determinados espaços por essa } \\
\text { comunidade. Para fundamentar nossa } \\
\text { análise, nos respaldamos no conceito de } \\
\text { paisagem semiótica que nos permitirá } \\
\text { compreender a presença e a interação } \\
\text { entre diferentes linguagens instauradas } \\
\text { no espaço público e as transformações } \\
\text { ocorridas nos locais para }\end{array}$ & $\begin{array}{l}\text { ABSTRACT: The cultural and economic } \\
\text { dynamics of the city of São Paulo, both in } \\
\text { the past and the present, has as one of its } \\
\text { main actors the otherness coming from } \\
\text { another country: refugees and } \\
\text { immigrants. Several immigrant groups } \\
\text { imprint their presence in the space of } \\
\text { different neighborhoods. This work aims } \\
\text { to observe and analyze elements of the } \\
\text { presence of immigrants and refugees } \\
\text { demarcated in the public space of São } \\
\text { Paulo neighborhoods, such as, for } \\
\text { example, foreign languages and the } \\
\text { immigrant trade. It is through these } \\
\text { elements that we can reflect on the } \\
\text { dynamics of the relationship between the } \\
\text { local and the global, with its } \\
\text { transformation or its denial through local } \\
\text { spatial instances. As a kind of case study, } \\
\text { still provisional, we examined a street of } \\
\text { the Bolivian community in the city of São } \\
\text { Paulo. We observe, initially, how there } \\
\text { are mixed practices that manifest } \\
\text { themselves both in linguistic use and in } \\
\text { the use of certain spaces by this } \\
\text { community. To base our analysis, we rely } \\
\text { on the concept of semiotic landscape that } \\
\text { will allow us to understand the presence } \\
\text { and interaction between different } \\
\text { languages established in the public space } \\
\text { and the transformations that take place in } \\
\text { the places to understand the dynamics }\end{array}$ \\
\hline
\end{tabular}

* Doutor em Semiótica e Linguística Geral pela USP, Professor do Programa de Pós-Graduação em Letras da Universidade Presbiteriana Mackenzie. ORCID: https://orcid.org/0000-0002-0798-3615. alexandrembueno@gmail.com; alexandre.bueno@mackenzie.br . 


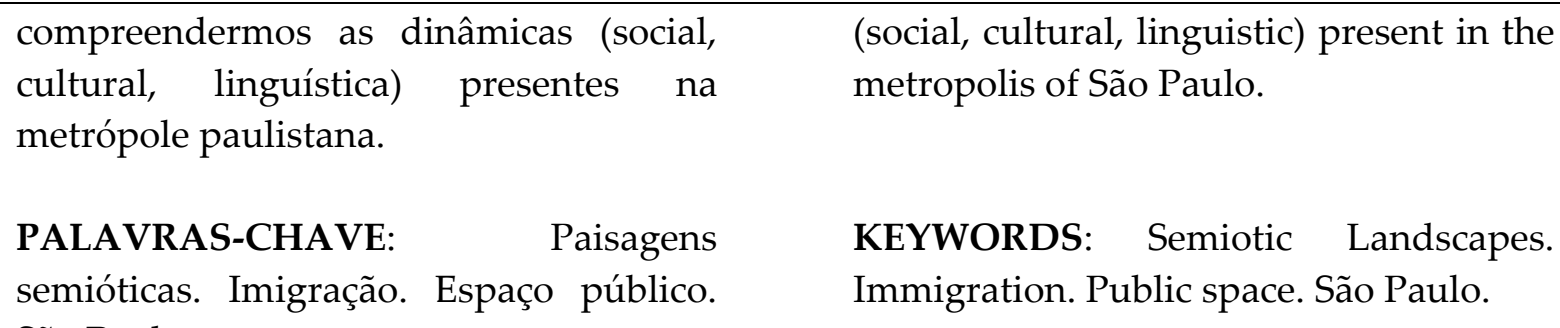

São Paulo.

\section{Observações preliminares}

São Paulo é uma metrópole cujos sentidos associados à imigração permanecem na ordem do dia. Além da presença de imigrantes na contemporaneidade, há elementos históricos que definem, em parte, a identidade de bairros paulistanos, como é o caso do Bom Retiro, da Liberdade, do Glicério, do Bexiga, da Bela Vista, da Mooca, do Brás, entre outros.

Podemos, assim, observar diariamente os fluxos de sentidos que perpassam essas localidades. Mencionamos, a seguir, dois fenômenos atuais para exemplificar as possibilidades de produção de sentidos ligados às questões do espaço, da identidade do bairro, da presença dos imigrantes e das tensões entre a historicidade e a globalização na contemporaneidade. O primeiro exemplo se refere à inauguração de um café gourmet ${ }^{1}$ no bairro do Bom Retiro (NAGASE, 2016), conhecido pela presença de imigrantes bolivianos, coreanos e de uma já estabelecida comunidade judaica que ainda permanece no bairro (apesar do amplo deslocamento que ocorreu em direção ao bairro de Higienópolis). O segundo é um bar-restaurante de refugiados sírios conhecido como Al Janiah, localizado inicialmente no Centro de São Paulo, próximo ao

\footnotetext{
${ }^{1}$ Há não muito tempo o substantivo "gourmet" passou a ser usado também como adjetivo. Um pouco como sua definição originária, a de apreciador de boas bebidas e comidas, o adjetivo se refere a um processo de requinte, em geral apenas aparente, de um objeto considerado banal ou comum. Dependendo do discurso, pode apresentar uma conotação negativa, de falso requinte ou de superficialidade em estabelecimentos que vendem a ideia de inovação e de valorização sem, de fato, sêlo, sobretudo pelo preço que é geralmente cobrado.
} 
Vale do Anhangabaú, e que atualmente se encontra instalado no bairro do Bexiga, reduto bastante conhecido da comunidade italiana de São Paulo.

A abertura do café gourmet no Bom Retiro provocou uma espécie de quebra na isotopia temática, figurativa e plástica do espaço de seu entorno no bairro, constituído predominantemente pelo comércio de roupas estimulado e mantido pelas comunidades coreanas e bolivianas. Em outras palavras, sua presença destoou, em termos comerciais e estéticos, daquilo que se espera de um lugar com um comércio bem estabelecido: o de roupas de baixo custo vendidas no atacado. Nesse caso, a entrada de um novo estabelecimento comercial desse gênero, que surgiu em grande número em outros bairros paulistanos (como Pinheiros e Santa Cecília), é a indicação de um possível processo de glocalização: "importar" um estabelecimento comum em grandes cidades europeias (como Paris ou Roma) e ressiginificá-lo com especificidades locais, evidenciadas, nessa adaptação paulistana, por meio de um tratamento plástico mais "refinado" de seu espaço e por comercializar cafés cujos blends foram cuidadosamente escolhidos para apreciação de um público distinto, ou seja, com poder aquisitivo maior. Assim, o que é comum a uma outra localidade (em um determinado país) se transforma e passa a ter outros sentidos (sociais, culturais, econômicos) quando concretizado em uma metrópole de um país periférico na dinâmica mundial.

O Al Janiah apresenta outras características que podem igualmente indicar caminhos para novas significações urbanas produzidas pela presença de novos grupos imigrantes. Ao ser inaugurado, o bar-restaurante, cujos proprietários são refugiados, promoveu a atração de um novo público para a centralidade urbana e produziu algumas transformações em seu entorno, como a promoção de shows de músicos imigrantes e de refugiados, produção de grafites políticos ao longo da rua, debates sobre as condições dos refugiados no Brasil e a atual situação geopolítica no Oriente Médio, entre outras atividades. Em relação à gastronomia, a popularização de pratos como o kebab (também chamado de shawarma) parece seguir o mesmo percurso do que 
ocorreu, décadas atrás, com os restaurantes japoneses (sashimi, sushi e yakissoba, entre outros) e italianos (massas em geral) em São Paulo $^{2}$ (e que parece também estar ocorrente com um prato típico da culinária peruana, o ceviche).

Desse modo, o surgimento de um comércio pode mobilizar outras significações no espaço local, ou seja, produzir uma nova diferença em relação às significações já existentes no bairro. Foram, inicialmente, esses dois estabelecimentos que nos provocaram alguns questionamentos: em que medida a criação de um novo comércio, distinto dos já existentes no entorno, começa a interferir na constituição identitária de um bairro, sobretudo naqueles em que há uma ligação histórica com as diferentes levas de imigrantes, do passado e da atualidade, como é o caso do Bom Retiro? Outros questionamentos, assim, surgiram, na esteira da pergunta inicial: os imigrantes e refugiados contemporâneos possuem algum papel nos processos de construção da significação existentes atualmente nos bairros paulistanos em que residem e/ou trabalham ou são alijados dessa experiência? E como a presença dos novos imigrantes e refugiados está transformando a paisagem urbana em bairros paulistanos?

Apesar da especificidade das perguntas, estudos sobre a relação entre imigrantes e espaços urbanos não é nova. Desde os estudos sobre Sociologia Urbana da Escola de Chicago, há toda uma literatura na Sociologia e na Antropologia que trata das transformações espaciais relacionadas à entrada de grupos imigrantes. $\mathrm{O}$ que diferencia nossa proposta é refletir sobre essas questões pelo viés das paisagens linguísticas e semióticas a partir de uma teoria que visa englobar essa discussão a partir de um quadro teórico único, derivado do encontro entre a Linguística (sobretudo a de inspiração saussureana) e as Ciências Humanas (Filosofia e Antropologia, principalmente). Estamos nos referindo à semiótica de linha francesa,

\footnotetext{
2 Poderíamos, assim, especular que a popularização da gastronomia desses dois últimos grupos imigrantes seria uma espécie de processo de glocalização avant la lettre, algo a ser mais bem refletido em trabalhos futuros.
} 
inaugurada por Algirdas Julien Greimas e desenvolvida a partir de diferentes colaboradores franceses e de outras nacionalidades. Assim, podemos atrelar à discussão das questões econômicas, políticas, sociais, culturais e linguísticas à noção de produção de sentido que atravessa todos esses temas em articulação com o espaço urbano.

A ligação entre alguns dos temas mencionados acima é apontada, entre outros, por Pezzini (2014), segundo a qual a presença de novos grupos imigrantes em uma cidade faz com que surjam novos imaginários cotidianos, além de nostalgias de conservação da população local. Além disso, essa presença também promove mudanças que afetam a materialidade da cidade (representada por prédios, praças, ruas, transporte público etc.), o que influencia as dinâmicas comunicacionais e a percepção simbólica da cidade e de seus habitantes.

A historicidade de alguns bairros é, assim, a base da identidade local que pode servir como elemento de resistência ou de ressignificação dos fluxos de sentido advindos da globalização e materializados espacialmente nas ruas desses bairros, sobretudo por meio do comércio, de instituições religiosas e escolares, da presença de diferentes línguas e sujeitos de nacionalidades diversas.

Com uma configuração multicultural e multilinguística considerada de antemão, surge a possibilidade de se compreender as significações existentes e em transformação nesses bairros por meio da noção de paisagens semióticas. Entendida como um conceito que sincretiza diversos sentidos, como o visual, o linguístico (verbal e escrito), o sonoro, entre outros, uma paisagem semiótica pode ser definida, ainda de modo superficial, como o estudo da presença de línguas, de linguagens e, consequentemente, de significações produzidas pela alteridade, sobretudo, presente no espaço público.

O objetivo deste trabalho é examinar a relação entre espaço e presença de imigrantes para a construção da identidade do espaço escolhido para análise e pensar 
também em como eles contribuem para a transformação da paisagem dos bairros em que vivem e/ou trabalham. Com o foco na construção espacial da significação, em que estão a presença da alteridade, este trabalho se propõe a uma análise inicial e experimental a respeito da presentificação de um grupo boliviano na cidade de São Paulo. Em especial, veremos a configuração linguística e semiótica no espaço público da rua Coimbra, localizada no bairro Bresser, na zona Leste da capital paulistana. Assim, aproveitaremos o espaço relativamente diminuto da rua para poder examinar as significações que ali são produzidas para a comunidade boliviana e para os brasileiros que por lá passam ou se estabelecem.

Antes da análise, passemos para algumas considerações teóricas, com o intuito de situar o lugar epistemológico a partir do qual desenvolvemos nosso trabalho e de onde dialogamos com outras teorias.

\section{Elementos para um conceito de paisagem semiótica}

Inicialmente, as paisagens são objetos construídos por meio da intervenção do homem (ARANTES, 2000). Dessa forma, elas se diferenciam da noção de território. Essa primeira distinção permite observar uma oposição de base na qual território está ligado ao valor da natureza (na medida em que pensamos que animais também possuem uma noção de território) enquanto a paisagem se relaciona à dimensão da cultura. Assim, o espaço não é mais encarado somente em seu aspecto físico, mas também como uma construção social dotada de significação.

Se há significação, é porque línguas e linguagens se tornam visíveis no espaço urbano, projetando-se sobre o lugar para articular sentidos inteligíveis e sensíveis. Essa é a razão para se tentar entender como as línguas e as linguagens, nesse caso, dos imigrantes e refugiados, em relação ou em confronto com a língua portuguesa, se manifestam no espaço público. Consequentemente, optamos por usar, para esse 
aspecto de nosso objeto, a noção de paisagens linguísticas como uma etapa do trabalho necessária para se chegar ao conceito de paisagens semióticas.

Paisagens linguísticas podem, então, ser entendidas como a diversidade de discursos verbais presentes no espaço público urbano. Um de seus propósitos é refletir sobre a maneira como diferentes línguas (a nacional e a dos imigrantes/refugiados) se relacionam no espaço urbano, revelando um caráter multilinguístico em determinados lugares. Além disso, um estudo sobre paisagens linguísticas permite compreender processos de (in)visibilidade de línguas estrangeiras e sua relação com a língua nacional de um determinado país, o que pode indicar relações implícitas de poder, desde as existentes no cotidiano até políticas linguísticas elaboradas pelo Estado. Ao mesmo tempo, diferentes línguas no espaço público contribuem para a construção simbólica do lugar em que surgem, ou seja, estabelecem ou ao menos contribuem para a construção da identidade do lugar (PEZZINI, 2013).

Estudos sobre paisagens linguísticas permitem, ainda, compreender como imigrantes e refugiados se tornam visíveis em uma região particular de uma dada metrópole. Dessa maneira, esses estudos podem mostrar que a ideia de uma homogeneidade linguística no espaço público se revela equivocada (PEZZINI, s/d, p. 4; PEZZINI, 2014, p. 8). Além disso, a manifestação de uma determinada língua estrangeira no espaço público pode apontar para o fato de que um determinado grupo começa a demarcar sua presença no local, o que envolve relações de conflito, solidariedade e poder entre os diferentes grupos estrangeiros (PEZZINI, 2014, p. 7).

Como uma das consequências, diferentes comunidades imigrantes espacializam de modo distinto o lugar, reorganizando o seu imaginário (PEZZINI, 2014, p. 11). Esse aspecto pode, muitas vezes, provocar uma reação dos habitantes locais que, por causa da nova diversidade de línguas presentes em seu espaço originário, começam a acreditar que a alteridade é uma ameaça (e até mesmo uma invasão) de seu espaço simbólico (PEZZINI, 20013, p. 2). 
No entanto, abordar os sentidos ligados à construção da identidade e da alteridade de alguns bairros de São Paulo somente por meio da visibilidade de determinadas línguas não nos parece ser suficiente, na medida em que pensamos que há também outros elementos que são tão importantes quanto à língua na construção das significações que desejamos esmiuçar. Assim, podemos ampliar a noção de paisagem linguística ao recorrermos ao conceito de paisagens semióticas, uma vez que elas abarcam aquela ao englobar outras linguagens manifestadas pela prática dos sujeitos e pela constituição plástica dos espaços, em consonância com o que afirma Pezzini (s/d., p. 4).

Observaremos como ocorre o cruzamento de diversas linguagens: línguas, visualidades e processos de espacialização (isto é, processos nos quais o espaço é representado imageticamente, organizado plasticamente e vivido pelos sujeitos que o habitam ou passam por ele) (PEZZINI, 2013, p. 2; PEZZINI, 2014, p. 8). Dessa maneira, pensar a paisagem semiótica em alguns bairros de São Paulo poderá nos indicar outros modos de compreender como se constituem as relações entre paisagem, identidade e interações sociais (PEZZINI, s/d., p. 5; PEZZINI, 2013, p. 2) em um contexto urbano, na medida em que são responsáveis pela constituição dessas significações.

A paisagem semiótica inclui também a atenção sobre a dimensão histórica do lugar, uma aproximação perceptiva (sobretudo visual, mas também sonora), uma estratificação da questão de relações que compreendem a identidade dos sujeitos e grupos e a relação com o poder (não apenas público, mas também aquele que orienta a relação com outros grupos sociais) (PEZZINI, s/d., p. 5). Além disso, segundo Pezzini (2014, p. 11), o espaço é, por meio do olhar histórico, continuamente reorganizado. Assim, a invenção e a reinvenção dos significados dos lugares é um processo intenso e complexo que inclui, mas sem privilégio ou hierarquização, a linguagem e o discurso.

Dessa maneira, o uso do conceito de paisagens semióticas nos permite compreender o espaço como o modo no qual as significações surgem, são 
transformadas ou entram em conflito nas relações entre a identidade local e os traços constitutivos das alteridades (de imigrantes e refugiados). Como afirma Pezzini:

(...) esta noção metodológica de 'paisagem semiótica' envolve a atenção para a dimensão histórica dos lugares, uma abordagem perceptiva sobretudo visual, uma estratificação de questões relacionais que dizem respeito à identidade dos sujeitos e de suas relações de poder. Além disso, a escolha deste termo manifesta, como já dissemos, a vontade programática dos analistas em focar, ao mesmo tempo, nas problemáticas do espaço dado e naquelas relacionadas à sua produção. E neste terreno nota-se bem como se poderiam gerar, de forma frutuosa, momentos de encontro e reflexão comum com as disciplinas projetuais (PEZZINI, 2013, p. 2)

Por fim, nosso projeto poderá tocar em uma questão ainda pouco trabalhada, sobretudo quando pensada nos estudos das espacialidades. Trata-se dos processos de tradução intersemiótica:

Devemos continuamente fazer as contas da alteridade dos outros com a alteridade que nós mesmos somos. Por isso, somos continuamente chamados a traduzir a alteridade, mas também a traduzir a tradição, a redefinir constantemente aquilo que acreditamos ser "nosso" (SEDDA, 2013, p. 143).

Em suma, pensar o espaço urbano, neste trabalho, é igualmente se debruçar nos processos em que significações são construídas e, em seguida, (re)interpretadas. Assim, pensar em uma São Paulo que articula a identidade e a alteridade é valorizar as diversidades de significações trazidas por imigrantes e refugiados, no passado e no presente, sobretudo em tempos nos quais podemos observar movimentos conservadores e preconceituosos que buscam apenas o estabelecimento da homogeneidade dos sentidos urbanos e sociais no país. 


\section{Um estudo de caso: a rua Coimbra em São Paulo}

Localizada no bairro Bresser, na zona Leste de São Paulo, a rua Coimbra tem por volta de 700 metros de comprimento e faz fronteira com as ruas Cesário Alvim e Dr. Costa Valente em suas duas extremidades (sendo ainda atravessada pela rua Bresser). Em relação às edificações, observamos casas residenciais (algumas transformadas em comércio, como se verá abaixo) e alguns poucos e pequenos prédios de uso misto (comércio no térreo e residências na parte de cima). A comunidade ocupa somente um dos lados do calçamento, pois o outro é ocupado por empresas de transporte e indústrias, cuja origem não foi claramente identificada por conta dos altos e longos muros sem identificação.

Abaixo, mostraremos como quase todo o comércio é dominado por bolivianos, o que talvez explique a pouca presença de brasileiros circulando na rua Coimbra e, principalmente, dentro dos comércios existentes na rua. Ao menos, essa foi a perspectiva que nos foi apresentada nas duas visitas que fizemos em junho de $2016^{3}$, sendo a última com uma câmera GoPro® para realizar as filmagens (o que também explica as fotografias em formato de "olho de peixe").

Atualmente a maior comunidade imigrante da capital paulista, os bolivianos inauguraram comércios em que diversos serviços estão disponíveis aos seus conterrâneos: desde comércios simples e tradicionais, como mercados e restaurantes, até serviços mais sofisticados, como casas de câmbio para remessas de dinheiro ao exterior. Mesmo diminuta, a rua Coimbra se tornou um centro de serviços importante para esta comunidade em São Paulo.

\footnotetext{
${ }^{3}$ Por conta de uma mudança de cidade para assumir o posto de professor em uma universidade no interior paulista, nos vimos obrigados a interromper a pesquisa. Contudo, no presente ano, retornamos à capital paulistana e, assim que o fim da pandemia permitir, retomaremos as visitas à rua Coimbra para elaborar um trabalho comparativo para observar as atuais transformações pelas quais o espaço certamente passou.
} 
Além disso, o comércio apresenta particularidades que não se limitam ao uso do espanhol. Na rua Coimbra, diversos estabelecimentos comerciais apresentam mais de uma funcionalidade: é comum observar um comércio que presta serviços tanto de turismo (viagens para Bolívia ou outras partes do mundo) como de remessa de dinheiro para o exterior (Figuras 1, 1a, 1b, 2 e 3). Ou ainda de aparentes bazares que vendem produtos de papelaria e ao mesmo tempo oferecem cartões para ligações telefônicas internacionais ou ainda que possuem cabines telefônicas para que seus usuários possam fazer a ligação ali mesmo, naquele instante (Figura 3).

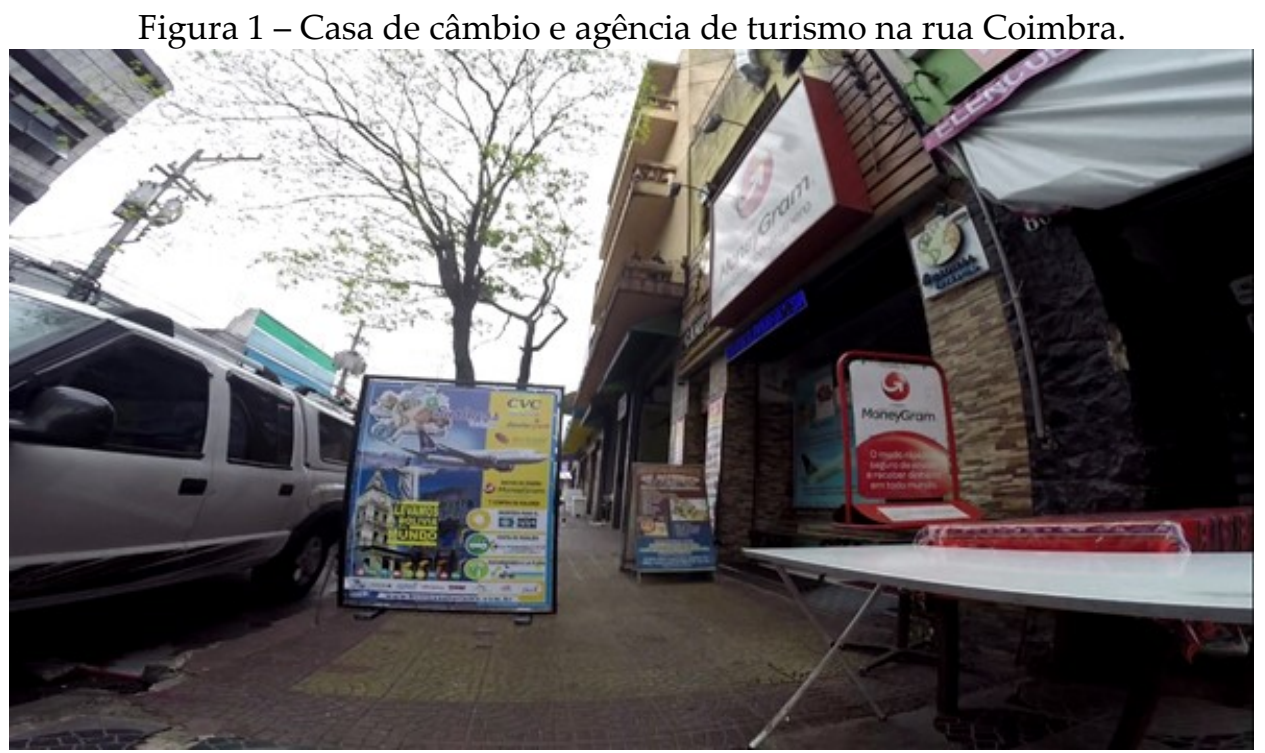

Comércio que comporta um tema financeiro e um tema turístico. Ambos coexistem no mesmo espaço de comércio.

Fonte: o próprio autor. 
Figura 1a - Detalhe da placa da agência de turismo em espanhol.

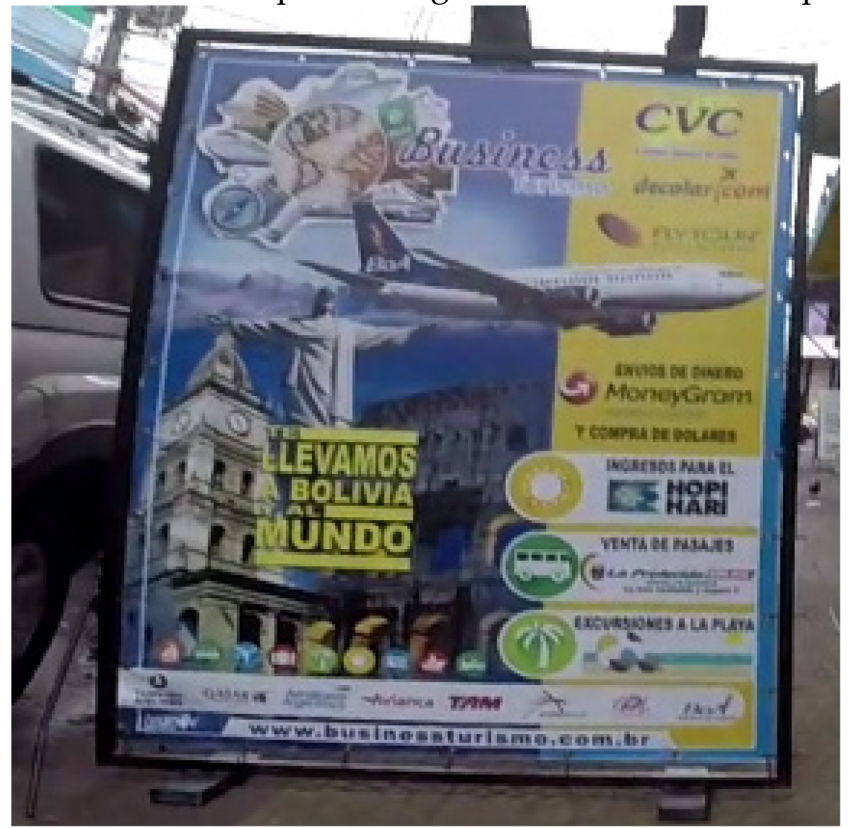

Fonte: o próprio autor.

Figura $1 \mathrm{~b}$ - Detalhe da placa da casa de câmbio em espanhol e em português.

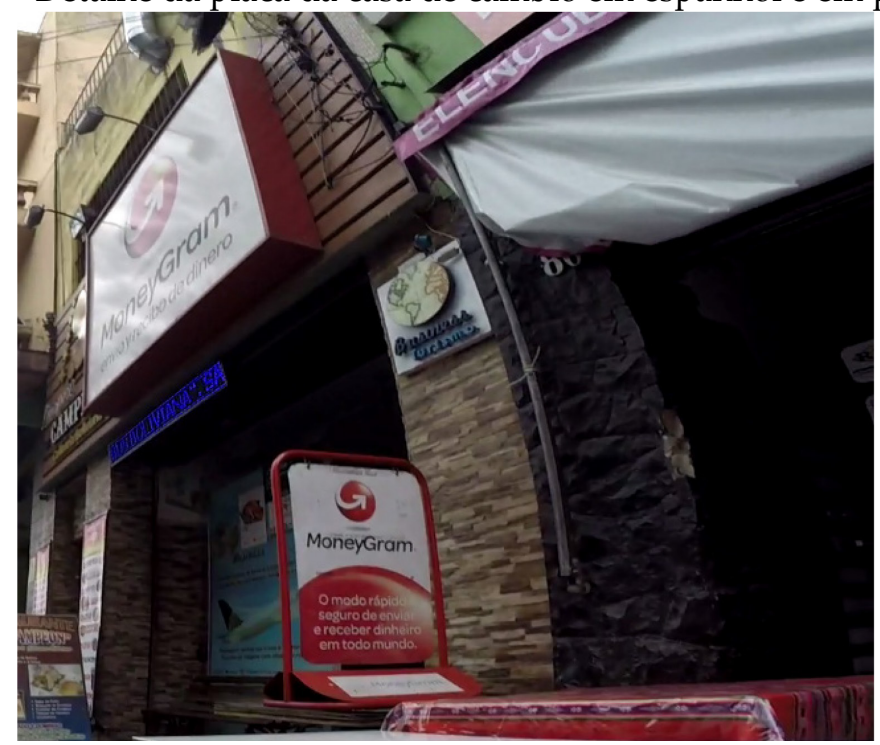

Fonte: o próprio autor.

${ }^{4}$ As figuras 1a e 1b são assim denominadas por serem destaques recortados da figura 1. 
Figura 2 - Outro estabelecimento comercial misto na rua Coimbra.

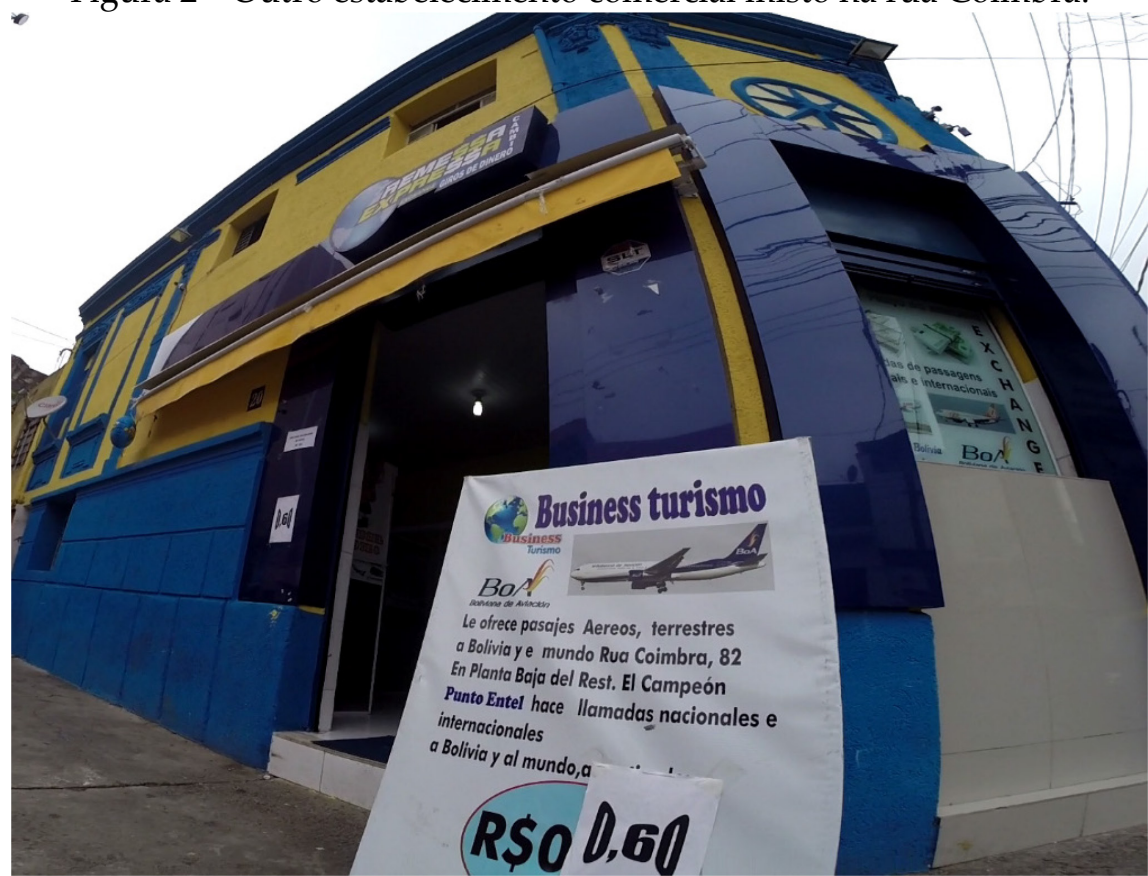

Fonte: o próprio autor.

Figura 3 - Terceiro estabelecimento comercial misto na rua Coimbra.

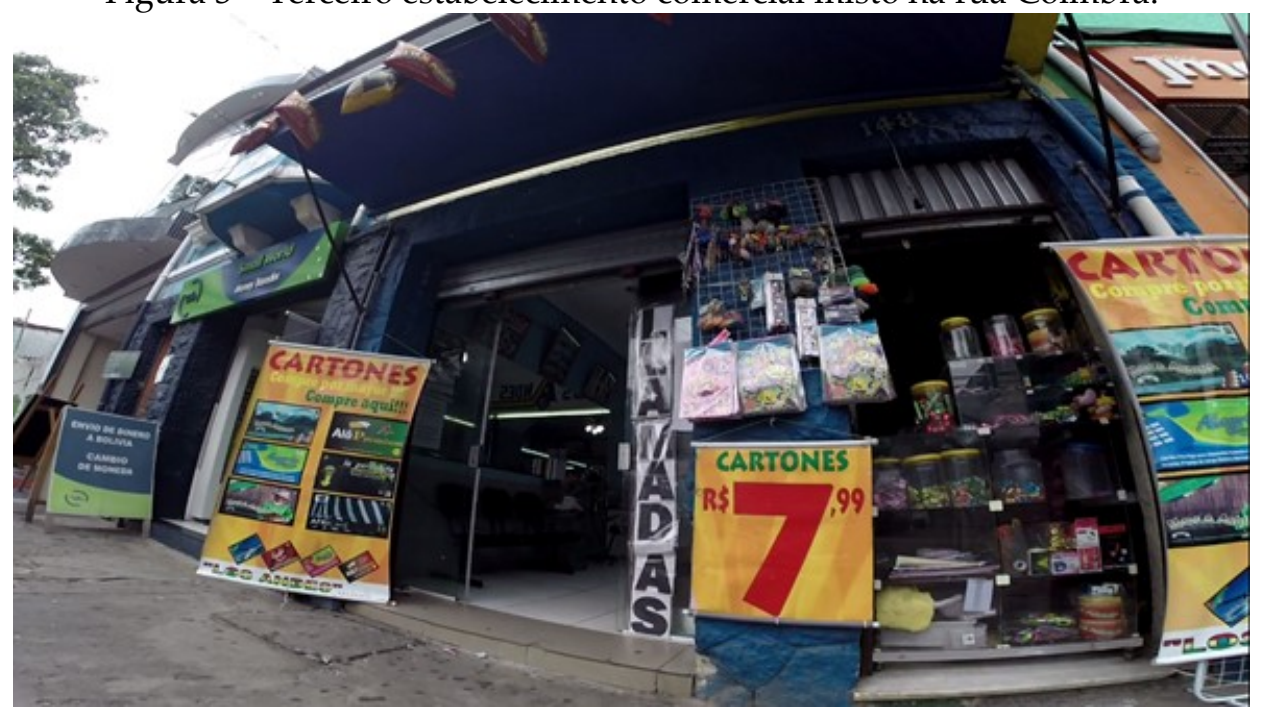

Comércio de venda de cartões de ligação internacional e de prestação de serviços telefônicos em coexistência com a comercialização de outros produtos, mais apropriados a uma papelaria. Fonte: o próprio autor.

Esse hibridismo de práticas possíveis em um mesmo lugar se deve, provavelmente, à necessidade de concentrar vários serviços no menor espaço possível. Além disso, há uma necessidade de atender as demandas básicas da comunidade, atitude que visa a tornar o comércio viável economicamente. Prova disso é que mesmo 
empresas conhecidas, como a CVC e a MoneyGram, possuem placas de identificação e de descrição de serviços em espanhol (Figura 1a, Figura 1b e Figura 2) (e em português, no caso da casa de câmbio da Figura 3). Dessa maneira, as empresas deixam claro para quem elas estão se dirigindo: para o público boliviano que vive na rua, no bairro ou que vai para aquele espaço em busca de um consumo de algo que eles conheçam, como é o caso também dos restaurantes bolivianos ali instalados. Além disso, as empresas visam, em alguma medida, manipular os passantes para que eles utilizem os serviços dessas empresas e, obviamente, o uso da língua materna desses sujeitos é o primeiro passo para se estabelecer contato entre a entidade comercial e seus potenciais consumidores.

No entanto, não há apenas comércios com essa constituição híbrida. Existem poucos espaços do comércio no qual sua função é única. Estes estão ligados aos restaurantes lá presentes (sobre os quais falaremos) e a alguns tipos de serviço, sobretudo os voltados à assessoria jurídica, conforme se observa nas imagens a seguir (Figuras 4 e 5). Interessante observar como, no caso da Figura 4, temos uma coexistência de línguas, mas demarcadas em lugares espaciais distintos: enquanto o espanhol está em uma placa improvisada na vertical, com cores chamativas, o português permanece no topo, na horizontal, logo abaixo do nome do escritório, com os serviços possíveis (declaração de IR, abertura de empresa com diversos estatutos jurídicos etc.). Além de uma distinção topológica, vemos que há também uma diferenciação material, na medida em que a placa superior se constitui como algo permanente, enquanto a placa na lateral tem um caráter impermanente, de algo que não conseguirá ficar por muito tempo naquela posição. De qualquer forma, o uso de tal placa parece ser uma estratégia para chamar a atenção de potenciais clientes, incluindo aqueles que não possuem o domínio mínimo do português. 
Figura 4 - Escritório de assessoria jurídica.

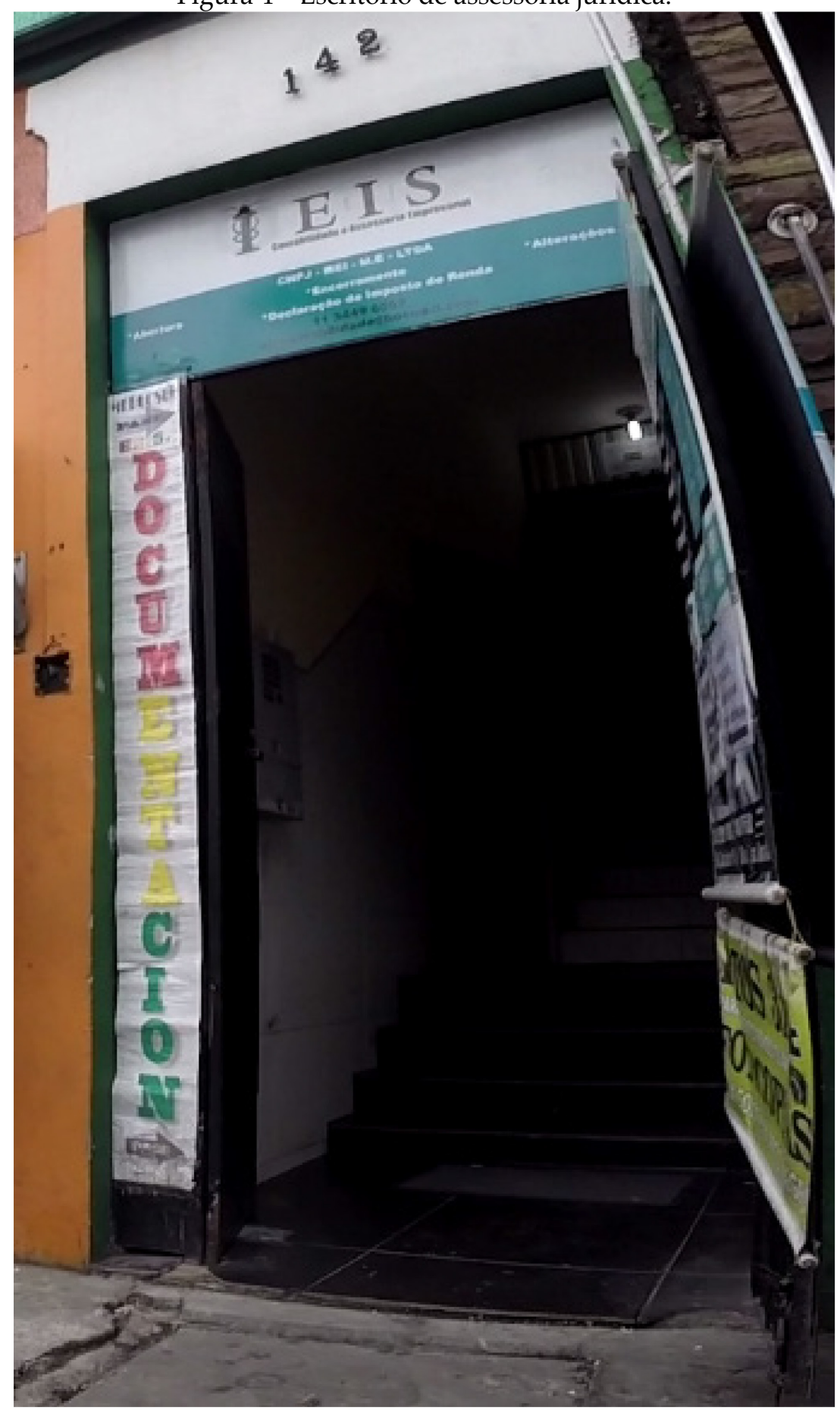

Fonte: o próprio autor. 
Figura 5 - Restaurante de culinária boliviana mais "simples" em comparação com o anterior.

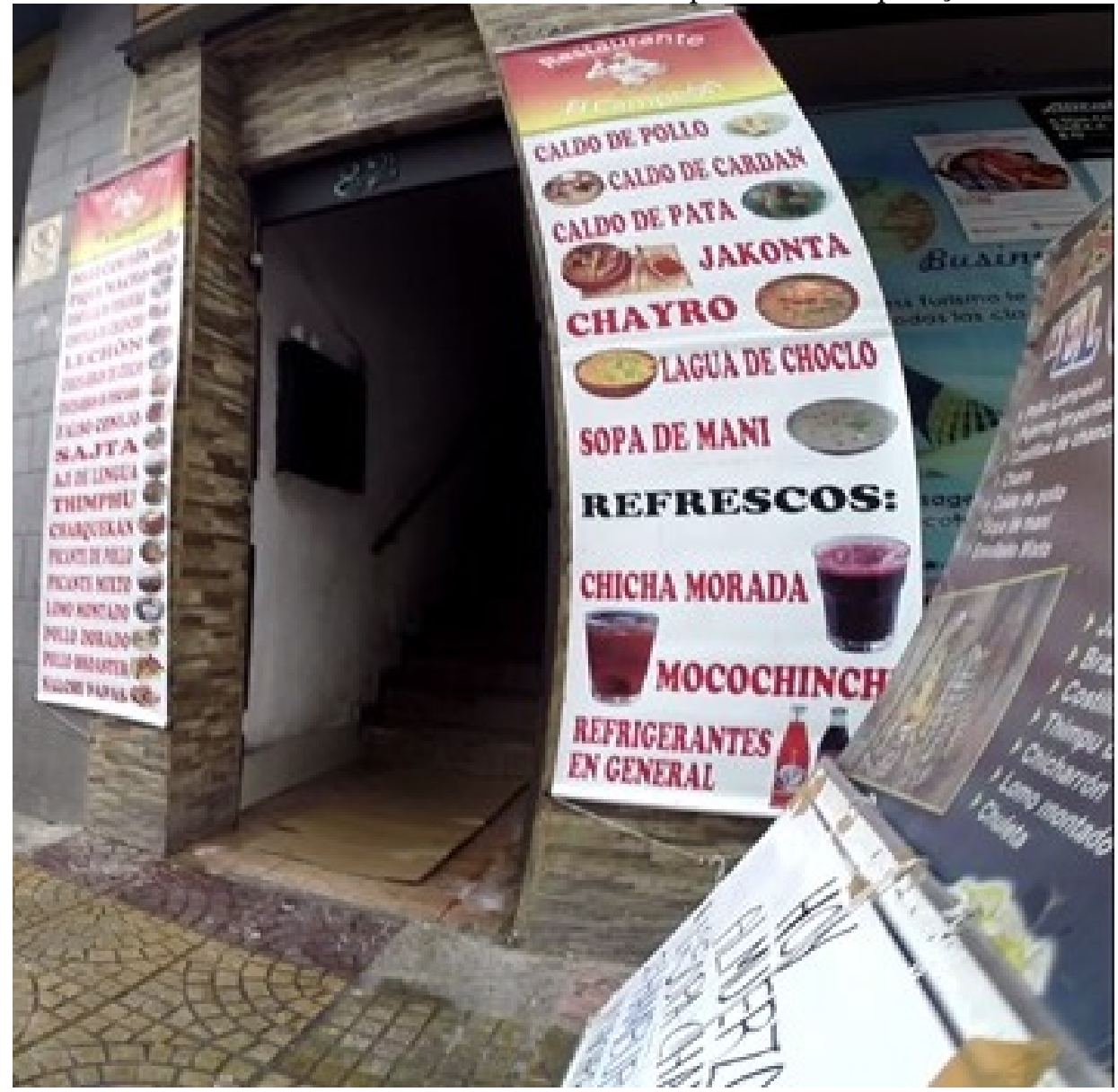

Fonte: o próprio autor.

Um outro fenômeno observado em alguns estabelecimentos é o uso misto do português e do espanhol, como no caso da Figura 5. Ao lado da palavra "refresco", mais utilizada em espanhol, vemos também a palavra "refrigerante", na frase "refrigerantes en general". Desse modo, podemos inferir, por esse uso, que pode haver uma tentativa de se usar o português em algumas situações ou que talvez isso seja derivado do desconhecimento do espanhol por parte de quem fez o banner.

Além disso, observamos alguns léxicos do aimará para se referir a alguns pratos da culinária boliviana, acompanhados de imagens dos referidos pratos. Assim, o cartaz parece se dirigir tanto a hispano falantes em geral, brasileiros e bolivianos em uma mesma situação. De qualquer maneira, vemos aqui um fenômeno talvez inverso: trata-se de comércios claramente bolivianos que podem estar querendo visar os 
consumidores brasileiros que eventualmente passam pelo local ou que moram na região.

A instalação do comércio, mesmo que híbrido (ou talvez por isso), na rua Coimbra, constrói os sentidos de um espaço mais funcional, onde os imigrantes podem se direcionar para realizar suas práticas de consumo, mais ligadas a uma intencionalidade pré-determinada.

O predomínio da composição do espaço é o da rede (LANDOWSKI, 2015), ou seja, como o espaço das trocas de objetos de valor, o que não impede de se passar também por experiências mais sensíveis, seja pela composição plástica do comércio, seja pela existência de um comércio "espiritual" presente para os que necessitam de tal auxílio (Figura 6).

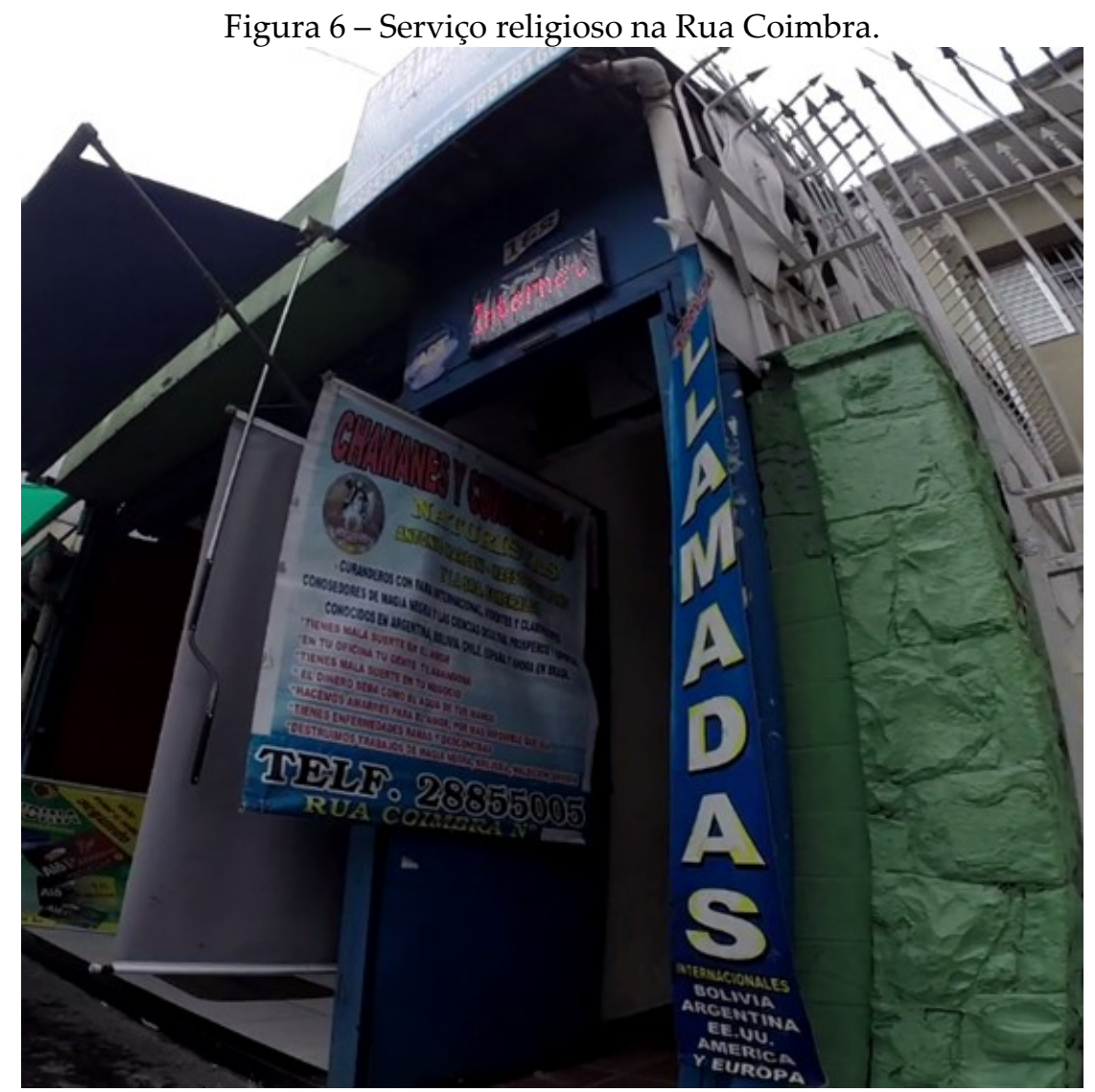

Comércio misto com prestação de serviço religioso e de chamadas telefônicas internacionais. Fonte: o próprio autor. 
Dessa feita, dentre os serviços oferecidos pelo local e o comércio instituído, há ao menos um que apresenta uma quebra (ou um desvio) na intencionalidade pura para a entrada do sensível ou ao menos de sua busca em um espaço mais geral no qual a persuasão racional ainda prevalece.

A partir dessas considerações, chegamos a duas constatações relativamente óbvias: a primeira se refere à percepção de que o imigrante não é apenas um trabalhador, mas também um sujeito que consome, que possui valores espirituais e alguém que tem seus momentos de descanso e lazer. A segunda trata de pensar que todas essas outras variações sobre o imigrante só se tornam possíveis porque eles criaram espaços específicos para a realização desses outros fazeres. Em outras palavras, somente com a criação de espaços próprios para os imigrantes e refugiados é que se torna possível a existência de tais práticas que relativizam o estereótipo do imigrante como sendo somente aquele que trabalha e não realiza qualquer outra ação ou não possui nenhum outro desejo.

Por conta dessa relação entre espaço e práticas que podemos também observar as transformações que os sujeitos realizam nos espaços nos quais estão inseridos. Eles, assim, podem criar sentidos para outros sujeitos que não estão frequentemente ali presentes, mas cujos sentidos podem atrai-los para preencher faltas de ordens diversas (simbólicas, linguísticas, objetais, subjetais etc.) ${ }^{5}$. Como afirmam Pezzini e Cervelli:

\begin{abstract}
Aliás, chegamos a considerar sua organização e seu enredo como o plano expressivo de uma linguagem própria e verdadeira que - não tanto enquanto substância, extensão, mas como forma construída - nos fala não só dos lugares, mas também da forma como certa comunidade - no nosso caso, artificialmente, uma ou mais marcas - organiza sua
\end{abstract}

${ }^{5}$ Contudo, a organização desses espaços não surge apenas quando os sujeitos se presentificam nele. Veremos ainda como a existência de práticas de reescritura, anteriores à presença dos sujeitos (religiosos, consumidores, de descanso) é fundamental para a existência desses espaços, apesar de não deixar as marcas de suas práticas. Podemos dizer que essas práticas de reescritura são fundadoras de espacialidades e que, se há uma possível narrativa nesses lugares, ela só existe por conta dessas práticas anteriores. 
própria estrutura e a relação com tudo que ela julga estranho, as relações intersubjetivas que a atravessam, os valores, éticos - mas também estéticos - com respeito aos quais ela se mede, o peso que ela atribui ao próprio passado e portanto à memória e ao futuro (PEZZINI; CERVELLI, 2007, p. 32).

Então, é nesse cruzamento entre práticas e espaços que os imigrantes podem criar, enquanto uma comunidade, suas especificidades e, de certa forma, elaborar simulacros que remetam às práticas diversas realizadas em seu país de origem.

Os destinadores, enquanto funções de articulação e de contenção de valores sociais, estão simbolicamente constituídos na rua Coimbra. Este caso se revela interessante pela posição espacial que a Associação de Empreendedores Bolivianos (ASSEMPBOL) ocupa na rua (Figura 7). Localizada na rua Dr. Costa Valente, a sede da associação fica em uma posição perpendicular em relação ao comércio da rua Coimbra, como se estivesse a todo momento observando o espaço da rua para melhor organizá-lo e controlá-lo. Ao mesmo tempo, ainda por causa de sua posição, a sede da ASSEMPBOL é visível de qualquer ponto da rua.

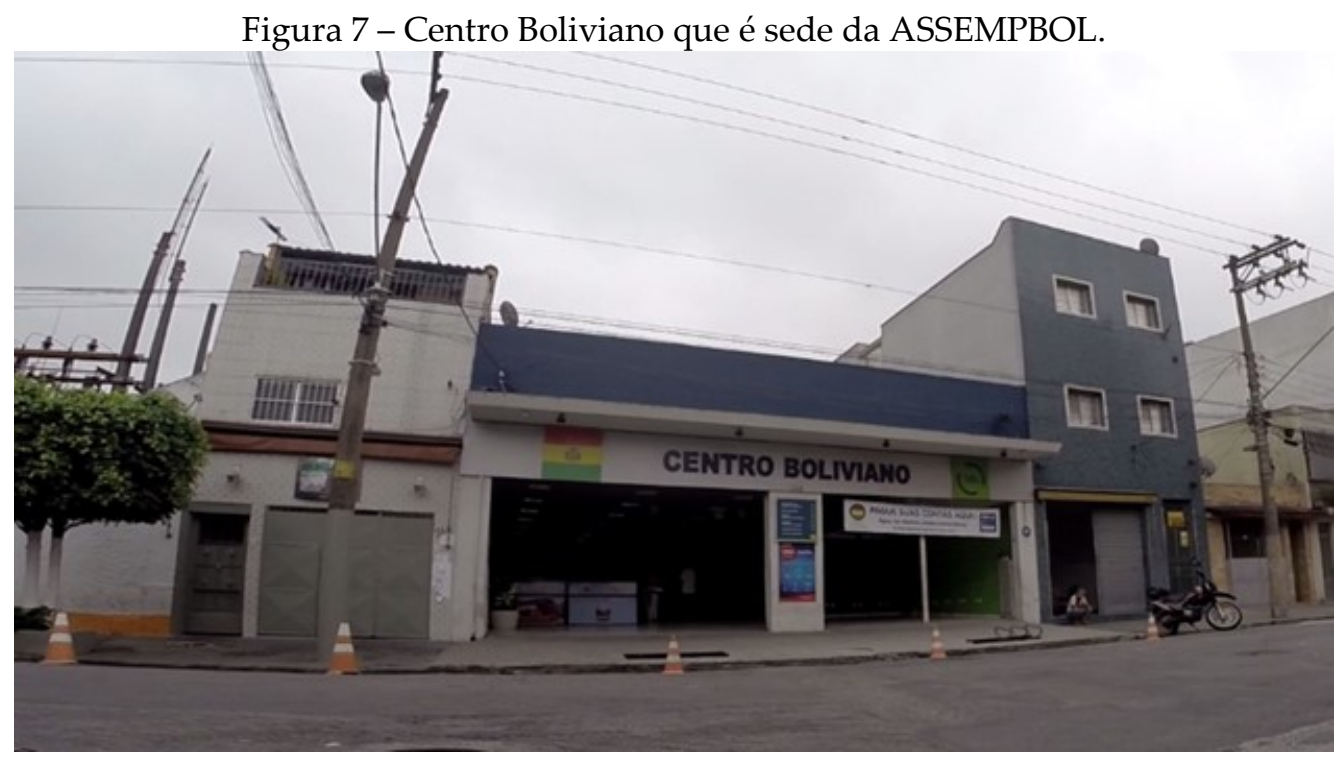

Centro Boliviano que fica na rua Dr. Costa Valente ao final da rua Coimbra ocupa uma posição de grande visibilidade em relação ao comércio.

Fonte: o próprio autor. 
Na rua Coimbra, em sua forma longilínea, torna-se um pouco difícil identificar o espaço, inicialmente, como "pertencente" a um determinado grupo imigrante, sobretudo a partir da esquina com a rua Bresser (via bastante movimentada por conta dos inúmeros comércios de roupa de cama, mesa e banho). Em primeiro lugar, porque em ambas as esquinas não há nenhum comércio ligado à cultura boliviana (pelo contrário, de um dos lados, à esquerda no sentido de quem parte do metrô, há somente uma longa parede do que parece ser de algum tipo de indústria). Em segundo lugar, porque a pouca circulação de pessoas nessa rua (em comparação com a acelerada movimentação presente na rua Bresser) faz com que o espaço não seja convidativo aos passantes e aos consumidores. Assim, somente um conhecimento prévio ou a mera curiosidade poderiam levar alguém até a metade da rua para, assim, começar a perceber que se trata de uma via com a particularidade instituída pela comunidade boliviana.

Por essa razão, podemos dizer que os espaços nos quais os imigrantes bolivianos realizam suas práticas são, ainda, espaços segregados (LANDOWSKI, 2002), ou seja, em quase completa disjunção com o restante de seu entorno, mesmo quando mais visíveis ao olhar brasileiro e paulistano. Em mais de uma oportunidade, observamos e mencionamos a pouca presença de brasileiros nesse local. Assim, apesar das possibilidades de interação e de trocas interculturais e interlinguísticas, os imigrantes continuam, de certa forma, segregados, apesar dos usos linguísticos mistos, que ainda não representam uma relação direta entre brasileiros e bolivianos, ao menos no espaço da rua Coimbra.

No entanto, podemos também entender essa segregação como uma forma de manter os sentidos ligados à origem comunitária dos imigrantes. Assim, podemos dizer que o elo que os une não é apenas inteligível, mas está ligado também ao contágio do sentido (LANDOWSKI, 2005): esses espaços seriam responsáveis pela criação de um contato reiterado com sua cultura de origem. Dessa forma, haveria uma 
atualização para uma realização efetiva dos sentidos articulados e sensíveis do familiar e do conhecido (mesmo que seja como um simulacro), que seriam compartilhados e praticados entre aqueles que, por algumas horas durante um dia, voltam a sentir que fazem parte de uma comunidade e, assim, a se reconhecer entre seus iguais. Esse modo de fazer os sentidos de origem circular só seria possível, justamente, por meio das espacialidades criadas pelos próprios imigrantes:

O espaço urbano, em suma, surge como dispositivo de construção e desconstrução incessante da subjetividade individual e coletiva, onde corpos, espaços e tecnologias mesclando-se em hierarquias variáveis - aparecem como atores de graus semelhantes, sujeitos precisamente, dotados de programas análogos de ação e de paixão (MARRONE, 2015, p. 35).

Dessa forma, para além das necessidades imediatas, haveria uma dimensão sensível que permearia tanto a interação dos sujeitos entre eles como a relação desses sujeitos com os espaços instituídos para se criar um sentido que remeta às significações de sua origem.

Vimos, então, que há uma dupla mistura possível na rua Coimbra. De um lado, a mistura de práticas comerciais. De outro, uma mistura de línguas, sobretudo espanhol e português.

\section{Observações parciais: São Paulo, uma cidade glocal?}

A presença de imigrantes mobiliza alguns sentidos. Dentre eles, pensar que a presença de estrangeiros é consequência da globalização que atinge, em maior ou menor grau, diversos países e reconfigura as relações entre eles. No entanto, pensar somente na globalização é escolher apenas um lado do processo, como se ele fosse unívoco quando, na verdade, ocorrem trocas e transformações de significações e valores. Assim, como afirmam Carmo et al. (2008, p. 341): "Para assentar de vez o 
conceito, teremos de quebrar com a visão hierárquica dos processos. O global e o local, o nacional e o regional (entre ouros confrontos), não podem continuar a ser interpretados como polos oponentes de uma mesma escala".

Por essas razões, mais do que globalização, optamos por falar em processos de glocalização. Sedda (2013) propõe, em uma chave semiótica, que o fenômeno da globalização seja examinado por meio de efeitos de glocalidade. Para se compreender a glocalidade, pode-se optar pela ideia de "efeitos de sentido relativos e relacionais" (2013, p. 134) em que participam hierarquizações e representações do poder, uma vez que o jogo entre o global e o local envolve sistemas e processos englobantes ou englobados. Haveria, assim, a necessidade de ser examinada a pluralidade desses efeitos e os níveis de homogeneidade e de heterogeneidade presentes nas tensões do glocal (2013, p. 134-135). Por isso, poder-se-ia encontrar localidades permeadas pelo global, assim como o global que não passa de uma localidade, ou seja, uma subestrutura dominante em um determinado espaço (a depender também do ponto de vista adotado) (2013, p. 136). No mesmo texto, ele trata ainda das políticas de identidade envolvidas no processo da glocalidade, pois esta seria, de certa forma, um dos possíveis efeitos presentes em tal fenômeno.

Entendida como um processo social, econômico, cultural etc., a glocalidade mobiliza diferentes operadores conceituais. Assim, Simões (2008, p. 131) defende que, nesse contexto, há generalizações do que é específico e misturas que produzem novas formas. Simões (2008, p. 142) segue ainda na defesa de que a globalização deve ser entendida como um processo de interpenetração cultural no qual estão presentes a plasticidade, a adaptabilidade e a criatividade. Em direção semelhante, Trivinho (2014, p. $34 ; 44$ ) defende a hibridização que anula as distâncias por meio das novas tecnologias mediáticas e reorganiza as misturas já existentes. Sedda (2013) trabalha com as noções de compartilhamento e de identificação como conceitos complementares às misturas e à hibridização. Esses e outros autores apontam, assim, 
para a multiplicidade de processos constitutivos da globalização, nos quais os movimentos imigratórios possuem um papel fundamental pelo que apresentam de potencial para acrescentar novas significações.

Dessa maneira, entendemos que a mistura de práticas em um mesmo espaço comercial, assim como o uso concomitante do espanhol e do português nos mesmos comércios são consequência desses processos de hibridização, misturas e interpenetrações culturais, econômicas e linguísticas. O que examinamos no presente trabalho foi apenas uma manifestação pontual de um fenômeno que esperamos observar futuramente em outras situações na cidade de São Paulo e, quiçá, em outras realidades urbanas no exterior.

No meio do processo de mistura desses fenômenos culturais e linguísticos, não podemos, então, perder de vista as relações entre o global e o local. Nesse sentido, Sedda (2013) também vai propor dois processos distintos, mas entrelaçados: globalizações locais e localizações globais. Dessa forma, localidades globais seriam as culturas que se sentem como globais porque os sentidos que circulam nelas parecem ser exclusivos delas, ou seja, os indivíduos participantes dessas culturas as consideram e as descrevem como representativas da humanidade em um sentido de totalidade que poderia se estender a outros grupos.

Já as culturas tomadas como globalizações locais seriam aquelas que apresentam uma tendência a se fechar em seu próprio espaço, não admitindo a presença da alteridade porque se baseiam na lógica dos valores próprios como positivos e os valores do outro como negativos (SEDDA, 2013, p. 132). Dessa forma, determinadas práticas culturais advindas da globalização teriam também, como consequência, a diversidade, o que criaria formas de autoidentificação coletiva (PEZZINI, 2014, p. 11).

Em suma, pensar a glocalidade em uma cidade como São Paulo é se dispor a tentar compreender processos dinâmicos nos quais o conflito, a transformação, a 
mistura e a reelaboração identitária dos espaços se torna uma constante cuja importância merece ser examinada com mais profundidade. Viver a cidade passa a ser, assim, vivenciar a experiência sensível e inteligível do que está originalmente distante (geográfica e historicamente), mas que se torna presente como diferença local reelaborada. Em direção semelhante, esperamos futuramente poder refletir sobre as consequências de tais presenças no espaço público urbano de São Paulo no processo de ressignificação constante pelo qual passa a maior cidade da América do Sul e que continua a receber todos os anos novos imigrantes que trazem consigo novas tradições, comportamentos, valores e, principalmente, novas línguas.

\section{Referências bibliográficas}

ARANTES, A. A. Paisagens paulistanas: transformações do espaço público. Campinas/São Paulo: Editora UNICAMP/Imprensa Oficial de São Paulo, 2000.

LANDOWSKI, E. Presenças do outro. São Paulo: Perspectiva, 2002.

LANDOWSKI, E. Regimes de espaço. Galáxia (São Paulo, Online), n. 29, p. 10-27, jun. 2015. DOI http://dx.doi.org/10.1590/1982-25542015122804

LANDOWSKI, E. Aquém ou além das estratégias, a presença contagiosa. Documentos de Estudo do Centro de Pesquisas Sociossemióticas, n. 3. São Paulo: Edições CPS, 2005.

MARRONE, G. Semiótica da cidade: corpos, espaços, tecnologias. Galáxia (São Paulo, Online), n. 29, p. 28-43, jun. 2015. DOI http://dx.doi.org/10.1590/1982-25542015122803

NAGASE, D. Nova cafeteria no Bom Retiro aposta em blend e torrefação próprios. Folha de S. Paulo. São Paulo, 08 jul. 2016. Disponível em: http://guia.folha.uol.com.br/guloseimas/2016/07/10003003-nova-cafeteria-no-bomretiro-aposta-em-blend-e-torrefacao-proprios.shtml. Acesso em: 08 de jul. 2019.

PEZZINI, I. Spazio pubblico, semiotica e paesaggio. s/d. Disponível em: https://www.academia.edu/11570887/Spazio pubblico semiotica e paesaggio BISP ROMA 2013. Acesso em: 23 ago. 2016. 
PEZZINI, I. Paisagens semióticas. Caderno de Discussão do Centro de Pesquisas Sociossemióticas (Cd-Rom), 2013.

PEZZINI, I. Nouveaux paysages sémiotiques et changement de la forme urbaine: perspectives de recherche à partir d'une étude sur Rome. Revue Degrés, 2014.

PEZZINI, I.; CERVELLI, P. Semiótica e consumo: espaços, identidades, experiências. Revista Galáxia, São Paulo, 29, n. 13, p. 29-45, jun. 2007.

SEDDA, F. Raízes, histórias e horizontes políticos do glocal. In: BUENO, A. M. ; FULANETI, O. N. (org.). Linguagem e política: estratégias, valores, interações e paixões. São Paulo: Contexto, 2013.

SIMÕES, J. A. de V. De várias malhas se entretece a rede global. Diferenciação cultural, sociedade em rede e internet. In: CARMO, R. M. do; MELO, D.; BLANES, R. L. (org.). A globalização no divã. Lisboa: Tinta-da-China, 2008.

TRIVINHO, E. (org.). A condição glocal: configurações tecnoculturais, sociopolíticas e econômico-financeiras na civilização mediática avançada. São Paulo: Annablume, 2014. 